velocity, i.e., a velocity to which apparently no limits can be set. It is true that the molecules which in the accidents of collision among themselves acquire these enormous velocities, have been mathematically proved to be relatively few in number, the greater number of the molecules possessing velocities approaching the mean value. But it wonld seem to follow necessarily that molecules situated in the top stratum of any atmosphere, and which acquire these enormous (indeterminable) velocities, can sometimes overcome gravity, and be projected into space, so as not to return; as it is a known fact that only a finite velocity is required to effect this result. I have therefore to suggest that by this cause the moon's atmosphere has gradually disappeared. It is probable, no doubt, that it would take a vast period of time to have brought about this result, but we have an almost un. fimited time at disposal. It might possibly be asked, How is it that the earth's atmosphere has not shared the same fate? In answer to this I would reply, first, that the value of gravity on the earth is known to be very much greater than on the moon, and second, that possibly (for aught we can tell) part of the earth's atmosphere may have thus disappeared; or the earth's atmosphere may be less dense at present than at one time, for anything we can say to the contrary. It would seem a curious fact to note in connection with this that there would be apparently grounds for inferring that the constitution or composition of the earth's (or any other planet's) atmosphere might have changed from the above cause, as evidently the lighter gaseous constituents, whose molecules acquire in the accidents of collision the highest velocities, would be first dissipated into space in the above manner. Thus, for example, any trace of that very prevalent constituent of the universe, hydrogen, that might have at one time existed in the earth's atmosphere, would have tended to become relatively rapidly eliminated, as the molecules of hydrogen are known to possess a normal velocity about four times as great as that of the constituent molecules of the earth's atmosphere. ${ }^{1}$ It might be said that changes so great as those above indicated are scarcely realisable, but then it should be kept in view that we have an almost limitless range of time to draw on, and it is generally admitted to be very important to take the effect of time into due consideration, as, for example, is done in the case of geology, where mountain ranges are recognised by incontrovertible physical wrof to have been carved out by the slow disintegrating action of rain and atmospheric inflnences prevailing through countless centuries. The gradual disappearance of an atmosphere (earth's or moon's) under the above cause might possibly be compared in slowness of operation to the other cosmical changes that the solar system is known to be undergoing, such as the gradual approach of the earth to the sun (and of the moon to the earth) through the friction of the material media in space, the accomplished stoppage of the moon's axial rotation by tidal action on its rnass, and the gradual diminution of the earth's rotative velocity from the same cause. These slow changes, imperceptible in the range of human experience, become important in large time epochs, and it becomes desirable in the interests of truth, in tracing back events, to give due weight to these time epochs. In sugyesting the above explanation, I have endeavoured ta confine myself strictly within the limits of mathematically proved facts as a basis to draw deductions upon, and I should be ylad to accept any criticisms that might be offered, either with the view to point ont a diffeculty or confirm the truth.

London, October

S. Tolver Preston

\section{Remarkable Local Colour-variation in Lizards}

THE following extract from a letter received some months since from Baron de Basterot, of Rome (a Fellow of the Geological Society of London), records an interesting case of local colour-vaxiation, about which some of your correspondents may be able to give us further information :-

"Capri is a mass of the usual yellowish-white Apennine limestone, forming precipitous cliffs nearly all round the island.

I The realisation of a possible diversity at a former epoch in the constitltion and density of the earth's atmosphere raises rather a curious question in connection with the known diversity of the plants and anmals that formerly inhabited the globe, as compared with those at present existing. It might be observed that admitting the possibility of the former existence of an atmosphere on the moon, it would seem to follow that an interchange of molecules berween the two atmospheres (those of the earth and moon) must have taken place at one time to a certain extent under the above cause, though the considerably less value of gravity on the moon compared with the case of the earth would facilitate the passage of molecules away from the moon. render correspondingly difficult the passage in the reverse direction.
At its southern extremity aie thee high and nearly inaccessible rocks called I Faraglioni, one of which, pierced by a natural arch, has been frequently depicted by artists. Two of these rocks are completely detached from the mainland, and, I need hardly add, uninhabited.

"On the island, and on the first of the Faraglioni rocks which is connected with it, the lizards are of the ustal species so common in Italy-colourea grey, mixed with more or less green. On the two outward Faraglioni rocks, which are completely separated from the shore, their colour is totally different. The back is of a blue so dark as to appear nearly black; the sides of a brilliant blue, like lapis-lazuli ; the belly light whitish-blue, with a very slight tinge of green.

"An English gentleman whom $I$ net in Capri had several of these Jizards alive, which had become quite tame in the course of a couple of months. I believe he intends bringing them to England. He is of opinion that they differ in colour only from the lizards of the island, and that, though very different in appearance, they are the same species.

"Whether this be so, or whether they are specifically difierent, their presence on these isolated rocks and their total absence on the islund is equally remarkable."

AlFRed R. WALlace

\section{Termites kept in Captivity by Ants}

75 When entomologising in Portugal in 1877 , in the neighbour hood of Cintra, I fonnd the nest of Formica nigra under a stone. On my turning it over there was, as nsual, great consternation in the community, and I discovered that it was evidently caused by the fear- lest a colony of Termes lucifugus, which the Formicas had enslaved, should escape. The Nigras instantly began seizing the Termites, driving them underground by the nearest orifices, in the meantime wrenching and pulling of their wings in the mos unceremonious manner. I observed a large number "of wings lying in heaps here and there in the nest as if this treatment had been practised before. In the nest there was also a great number of Termite larve. The great object of the owners of the "location" seemed to be to get these larwa nudergrotind as speedily as possible. The ants fell on them with great impetuosity, seizing them anyhow and anywhere, dragging them against the most strenuous opposition (their belizaviour strikingly contrasting with the meekness of their winged fellows) into the nearest apertures of the underground home. Very often this opposition resulted in a long and stem fight, in whicl the larva were often badly wounded, being deprived sometimes of their antenna, sometimes of half their jaws, and not seldom lilled outrigit? Occasionally, however, the latve were victorions, beating off the Formicas, in which case they (the larva) did not make off, but remained perambulating the nest. I saw one larva drawn at the end of a long fight by its antenna, while it strenuously held on to a small ball of eartly which had proved a vain anchorage for its feet, for larva and clod together were diagged across the top of the nest (made by the impression of the stone) five or six inches, up the side, I inch, and away among the grass, where, losing the ball of earth, it seized a stalk so frrmly that its abductor could wot drag it farther, whereupon, after reconnoitring the ground for a little distance the latter disappeared, but returned shortly with a companion, with whose aid the larva was detached. This done the helper returned home while the abductor proceeded with his prisoner till lost to view in the grass, some twelve or fourteen inches from the spot whence it originally started.

In the same neighbourbood I watched for some time a nest of Fornica ligniperda. An injured female was placed in the nest, but no assistance was rendered, while it crawled along towards the nearest orifice leading underground. At the spot where this individual was injured some of the fluid of its body which had oozed out was eagerly lapped up by the others; some even applied their mouths to the wounds on the body. During the operation of lapping the maxillae were kept perfectly still, and the antenne close to the side of the head "feel-feeling" the gronnd with the tips, as if to discover the spot where the liquid was to be found. Every now and then, however, they were extended at right angles to the body, as if to obtain a more general survey of things, and then immediately returned to their previous position. On several of those which were busy lappino I poured some spirits of wine. They instantly became stupefed, and for a time motionless. When in this condition they were 
visited by many of their fellow colonists, who, having eursorily examined them, fell to touching them with their antemx on the abdomen, reminding me much of a mesmerist making passes over a victim. The effect was almost electrical. I was sur. prised to see the incapables at once begin to rally. After stretching their legs and moving their antennae they moved along slowly for one or two steps and then went along as if nothing had happened. Others came and drank of the spirit not quite evaporated, but did not seem to suffer any bad effects. I buried a member of the community as it was in the act of carrying off a larva. Although many came and looked on none took compassion or attempted to relieve their friend. A small heap of larva, however, which I pressed down into the soft earth with my pencil, thereby injuring some of them badly, was disinterred, and every individual carried into a place of safety.

A stranger placed in the nest was very soon set upon, and before long its head was travelling on a direction opposite to that of its abdomen. The headsman's reward was a long draught of blood from the severed abdomen.

On my turning over the stone at first, the larva were exposed, but were soon begun to be carried off. Some of the workers were certainly busybodies, fussing about, pretending to do a great deal, while in fact they were shirking their fair share of the household duties. They wonld rush at the larva, seize one and be off with it in a great hurry, but they had not gone far (not even always in the direction of the entrance) before they changed their minds, threw down their load to return for another helpless infant, which was treated in the same way, being carried generally in a direction contrary to the previous, and dropped down anywhere, sometimes begond the linits of the nest altogether.

My observations with regard to ants clropping intentionally or jumping from small heights do not quite agree with Sir John Lutbock's, but they are not yet full enoutgh to give in detail. I hope to have fuller opportunities for the investigation of the habits of this most interesting class in the Malayan Archipelago, whither I am now bound.

Meantime I hope these few notes may have some interest for the readers of NATURE.

S.S. Cilcbes, off Naples, October is

\section{Colour-blinỏness}

HAS it been suggested that the traditional blindness of Homer may have been-in the absence among the ancients of a specific name for colour-blindness-mizerely the colour-blindness for which Dr. Pole makes out so good a case? To readers ignorant of Daltonism, blindness must have appeared the only explanation of a glaringly misapplied colonr-epithet. It is at least clear that the author of the Homeric poems was not always blind in the modern sense of the word.

Brighton, November I

Clementiya Blach

THE conclusion of Dr. Pole's valuable paper will doubtless stir up many to investigate the guestion whether or not dichromatisn was the rule at an early stage of human vision.

Will you allow me to adduce, towards the solution of this question, the evidence of a literature, which though not nearly so ancient as the Greel, goes back further than that of many European nations. I mean the Irish. I find in some of the earliest works in that language an ambiguity in the application of adjectives of colour very similar to that noticed in the Homeric writings by Mr. Gladstone. Glas, for instance, is used, indifferently, apparently, for green, grey, and blue. Uaithne is used to indicate the colour of grass, and also that of the hmman eye. Dearg is employed to denote the colour of wine, and also that of clay, Ruadls (red) is similarly ambiguous.

I82, Adelaide Road, N.W.

EDMUND MICLURE

\section{Carrier-Pigeons}

IN NATURe (vol. xviii. p. 682) it is stated that carrier pigeons are being "turned to useful account" in a new cirection in Germany, for Consul Ward writes to the Foreion Office " that the successful results attained by the establishment of communication between the two Eider lightships and the Port of Tumning, in
Schleswig, by these means has led to its organisation" elsewhere. This mode of communication is, however, not new, as carrier-pigeons were employed early in this century as a means of communication with the Bell Rock Lighthouse, as mentioned in my late father's "Account" of that work. The pigeons passed between the lighthouse and the shore-a distance of eleven miles in eleven minutes. The employment of these birds, however, was, I suppose, found to be more curious than convenient, for they have long since ceased to be employed. The pigeons were presented to the establishment by the late Sir Samuel Brown, R.N.

Edinburgh

THOMAS STEVENSON

\section{Globular Lightning}

As the curions phenomenon known by the above name seems to be attracting some attention just now, I venture to send you the following details, which, though of rather ancient date, are still, owing to their startling character, very fresh in my memory.

I think it was in the year 1866, in the beginning of the month of August, that I was walking in the garden when the atmosphere became exceedingly oppressive (there had previously been a very long dronght), and thinking by the appearance of the sky, which looked lurid and threatening, that a storm was coming on, I made for the house. As I was going up our front steps some rain-drops fell, which were the largest I ever saw. I had just reached the dining-room and was standing near the window, which looks north, when I saw a large ball of fire, which appeared to me, looking at it as $I$ did from a distance, to be the size of a globe such as is used in schools, descend towards the earth. In descending it siruck the church, which is immediately opposite our house, and brought with it a number of slates and part of a stone cross, maling a terrific noise. There was a flash of lightning soon after, followed by a moderately lond clap of thunder, but nothing more. As there were not at that time any houses near to ours $I$ did nut hear the occurrence mentioned by any one. The noise, though extremely loud, was not at all like thunder. The illomination of the rooms by the bail of fire was seen by two other persons in the house.

St. John's Road, Putney, S.W.

Charlotte Hare

\section{Speaking-Trumpets}

THe antigiaty of the speaking-trumpet masy be proved tipon far bigher authority than that of the inmaginative Athanasius Kircher. It is literally as old as the pyramids. While exar mining Lepsius's great work upon ancient Egypt for my "History of Music" I noted two examples among the plates of the fourth dynasty of Egypt (see Lepsius's "Denkmäler," Dyn. 4, Abt. 2, Blatter 27 and 30l. The Eoyptian speakingtrumpets seem to have been some five feet or more in length, and too wide in diameter to have been blown by the mouth. They are conical, and lack the contraction near the mouth end which is so observable in their war-trumpets.

Wri. ChappelL

\section{Toughened Glass}

MY own experience supports the necessity for caution in using Bastie's toughened glass. Shortly after its introduction I had some graduated messures, and although they were sufficiently tongh to bear the shock consequent on falling five or six feet to the ground, yet after a time some short scratches appeared on their surface, and these rapidly spreading till they nearly covered the whole of the glass, when but a slight touch was sufficient to make the measure fly into fragments. One placed on a shelf subject to rather rapid change of temperature, without any handling or apparent cause, broke up suddenly into tiny pieces, behaving, indeed, as if it were a Rupert's bomb.

$$
\text { Northampton, October } 29
$$

G. C. DRUCT

\section{POTTERY AT THE PARIS EXHIBITION}

$T H E$ extensive collections of pottery at the Paris Exhibition brought together from so many countries, is of high interest from a technical, as well as from an 